\title{
Control del colapso del colágeno: sistemas autograbadores
}

\author{
Sánchez Aguilera F*, Osorio R**, Toledano $M^{* * * *}$
}

\section{RESUMEN}

Con el grabado ácido se obtiene un frente de desmineralización con un grosor diferente y mayor que el frente de infiltración de la resina, dando lugar al colapso del colágeno. Para solventar el problema aparecieron los sistemas autograbadores que a medida que desmineralizan van infiltrando la dentina. Se caracterizan los autograbadores dentro de los sistemas adhesivos y se analizan las fuerzas de adhesión que producen y los factores de que depende la profundidad de desmineralización de sus imprimadores.

Palabras clave: Sistemas adhesivos autograbadores, profundidad de desmineralización, resistencia adhesiva.

\begin{abstract}
When dentin is etching the former (depth of dentin demineralization) excess the latter (depth of dentin diffusion / impregnation), a zone of hydroxyapatite depleted collagen fibers is left exposed, i.e., not resin infiltrated and nonhybridized. To avoid this, one option are the self-etching dentin bonding systems, that decalcify the inorganic component and infiltrate the collagen fibers at the same time by the action of acidic primers. In this article, the selfetching systems are characterized, and, their interfacial bond strength and the depth of demineralization of acidic primers are analysed.
\end{abstract}

Key words: Self-etching bonding systems, depth of demineralisation, bond strength.

Aceptado para publicación: Octubre 2003

* Profesora Asociada. Facultad de Odontología. Universidad de Granada.

** Profesor Titular. Facultad de Odontología. Universidad de Granada.

*** Profesor Titular. Facultad de Odontología. Universidad de Granada.

Sánchez Aguilera F, Osorio R, Toledano M. Control del colapso del colágeno: sistemas autograbadores. Av. Odontoestomatol 2004; 20-4:175-183.

Clarificar el panorama actual de la adhesión o investigar la existencia de una panacea en la vanguardia de la Odontología Adhesiva es un objetivo muy loable pero imposible de conseguir en la actualidad. Las últimas tendencias hablan de sistemas autograbadores: ¿Qué hacen realmente los autograbadores? ¿Qué nos pueden ofrecer entre la tormenta de productos que nos llegan a diario a las consultas? ¿Cómo pueden ayudar a mejorar la adhesión en general?

\section{EL PROBLEMA DE LA ADHESIÓN}

Para comprender cómo fue la incursión de los autograbadores (conocidos en la literatura anglosajona como self-etching) en el mundo de la Odontología se debe recordar que un agente grabador es "aquel agente químico que se coloca y que posteriormente se elimina de la superficie del esmalte y de la dentina para conseguir, teóricamente, un sustrato más útil en el procedimiento de adhesión". El grabado 


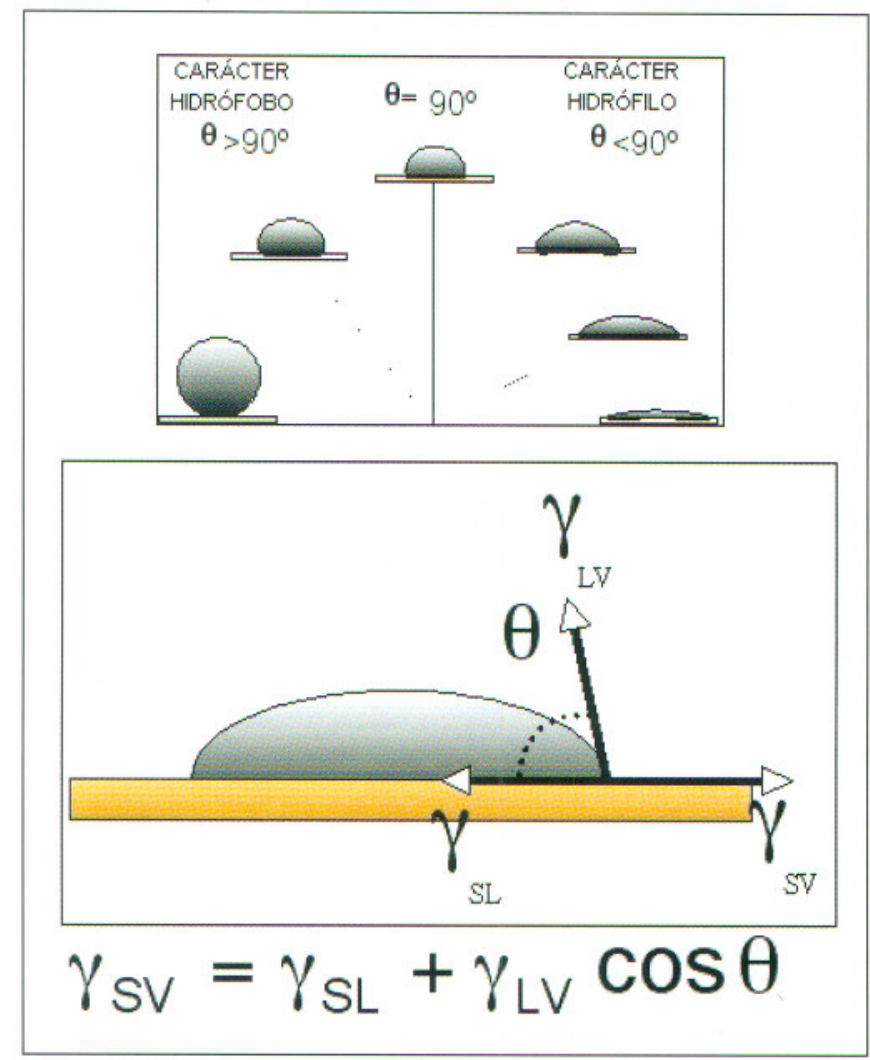

Fig. 1. Interacción e influencia del ángulo de contacto entre el sustrato y el adhesivo.

ácido en el esmalte genera una superficie óptima para la adhesión. En la dentina, donde la mitad de la materia es orgánica junto con agua, las dificultades para la adhesión aumentan. 1) En primer lugar se obtiene una remoción del barrillo dentinario o smear layer (1). 2) En segundo lugar se pretende crear una desmineralización de la capa superficial de la dentina, eliminando así tejido mineral. 3) Además se pretende conseguir una apertura de los túbulos dentinarios, exponiendo la luz del túbulo y aumentando su diámetro con la seguridad de una mayor entrada posterior de resina. 4) También quedaría expuesta el entramado de fibras de colágena para posibles encadenamientos con las resinas de los adhesivos, fibras de colágena, que según algunos autores, suponen el verdadero sustrato de adhesión a la dentina. 5) Se persigue el aumento de la rugosidad intertubular del sustrato, es decir, un incremento en las rugosidades de la dentina grabada, con lo que se consigue aumentar la superficie para la adhesión y hacerla más anfractuosa. Este punto queda perfectamente reflejado en el estudio de Toledano y cols. (2), en el que evalúan el ángulo de contacto de la superficie dentinaria embebida en dos adhesivos autograbadores y un adhesivo de tres pasos, que requería el grabado ácido de la dentina. La humectabilidad es un término general usado para indicar "la capacidad de un líquido de establecer un contacto íntimo con la superficie de un sustrato sólido". Se dice que un sustrato sólido es humectable (o en otros términos más "mojable") si tiene un ángulo de contacto pequeño. Y existirá una buena unión adhesiva si la humectabilidad (o el íntimo contacto) es efectiva entre el adhesivo líquido y la superficie de dentina acondicionada; es decir, debemos tener el ángulo de contacto más bajo posible (3) (Figura 1).Cuando se graba con ácido la dentina se obtienen ángulos de contacto más bajos que cuando se utilizan sistemas adhesivos autograbadores; es decir, se obtiene una superficie más mojable, un mayor contacto íntimo cuando se emplea un adhesivo de tres pasos en que se usa un agente grabador que cuando no es así.

A pesar de todo ello, no se obtienen los valores de fuerzas de adhesión esperados. Las primeras resinas adhesivas (antes incluso del grabado ácido) penetraban en las porosidades de la superficie rellenas de agua muy pobremente, debido al hecho de que la mayoría de los primeros sistemas adhesivos se basaban en resinas hidrofóbicas. Los valores de adhesión que ofrecían eran bajos (2-5 Mpa) y su estudio bajo Microscopía Electrónica de Barrido (MEB) indicaba que cuando se producía el fallo lo que se medían realmente eran las fuerzas de cohesión de los constituyentes propios del barrillo dentinario. Esta comprensión pareció establecer un límite en las fuerzas de adhesión que se podían llevar a cabo manteniendo el barrillo dentinario, y aceleró el desarrollo de sistemas de adhesión que removiesen parcial o totalmente el barrillo dentinario, evitando esta limitación (4). Con la aparición del grabado ácido se obtiene un frente de desmineralización con un grosor diferente y mayor que el frente de difusión/impregnación o infiltración de la resina. El primero de ellos dependería del tipo de ácido, del tiempo de grabado, del tipo de dentina subyacente así como del espesor del barrillo dentinario, que dependen de diversos factores (del tipo de imprimador, del tipo de solvente, del tipo de técnica que se esté empleando,...). Pero con el aumento de las fuerzas de adhesión, se da lugar a la aparición de un frente de desmineralización a partir del grabado ácido cuyo espesor es mayor que el 


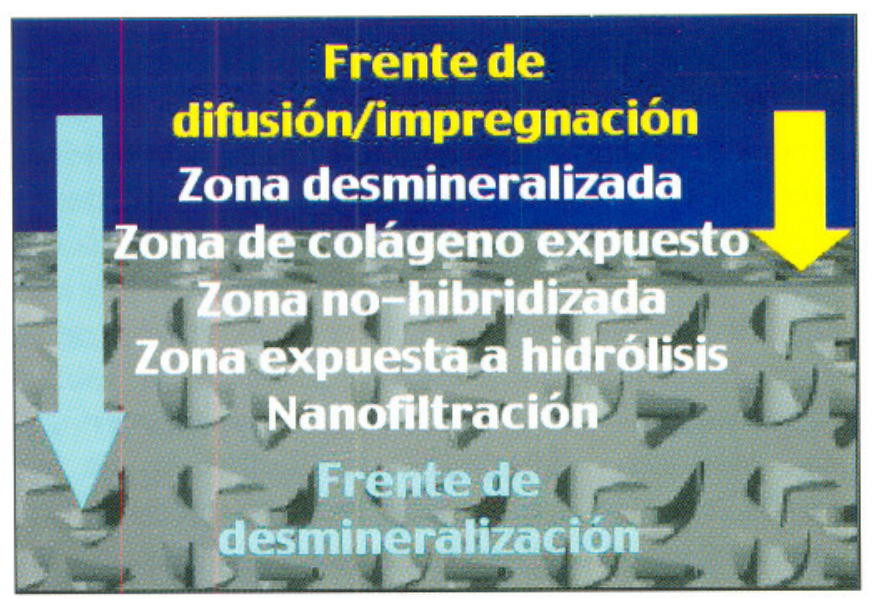

Fig. 2. Esquema de la zona desmineralizada y no infiltrada de la dentina, y efectos negativos que tienen estos adhesivos sobre la dentina y la propia adhesión.

frente de infiltración de las resinas adhesivas. Eso supone que las fibras de colágena de la base puedan quedar desprotegidas y expuestas, puesto que se trata de una zona de dentina desmineralizada y no infiltrada, es decir, un zona no hibridizada, ya que no tiene resina. Todo ello da como consecuencia que esta zona es muy susceptible a la hidrólisis y a la fractura cuando las preparaciones se someten a pruebas de resistencia mecánica. A la larga, esta región de colágena sin hidroxiapatita y sin resina puede ser la responsable de fracasos en las restauraciones. La presencia de bacterias en esa zona puede afectar a esa base de la capa híbrida que está desprotegida y puede ser susceptible de procesos de degradación hidrolítica o degradación a partir de ácidos y enzimas eliminados por las bacterias dando lugar al conocido como fenómeno de nanofiltración (1) (Figura 2), en definitiva, un aumento de la permeabilidad a través de los túbulos y la dentina intertubular y, por tanto, un aumento en el potencial de irritación pulpar si la unión ha sido imperfecta (4).

Todo este problema junto con el interés en simplificar el número de pasos en los protocolos de adhesión, la relativa alta sensibilidad a la técnica en estos adhesivos y la aparente dificultad para solventar el compromiso de una unión igual de efectiva a esmalte y dentina dio como origen la aparición de los sistemas adhesivos autograbadores.

El desarrollo de los autograbadores ofreció la posibilidad de incorporar el barrillo dentinario original a la capa híbrida. Teóricamente en un sistema adhesivo que simultáneamente desmineraliza la dentina y la infiltra con monómeros que van a ser polimerizados "in situ" no debe permitir la aparición de gaps, de este desfase, entre la dentina impregnada y el frente de desmineralización subyacente de la matriz de dentina. El resultado es un procedimiento de adhesión simplificado que mejora el sellado marginal y la adhesión a dentina (5). Los primeros monómeros de resina que se combinaron con acondicionadores ácidos lo hicieron con ácidos débiles como el ácido nítrico o el maléico (ScotchBond 2, Syntac). A continuación se investigó una proporción sobre un $5 \%$ de monómeros de resinas hidrofílicas con radicales ácidos, tales como el phenyl $\mathrm{P}$ o el MDP, pero en la actualidad dado que la profundidad de desmineralización no era satisfactoria, se están estudiando sistemas de autograbadores con el aumento de la concentración hasta un $20-30 \%$ de resinas ácidas, llegando a alcanzarse valores de fuerzas de adhesión de hasta 25 Mpa (4).

\section{CLASIFICACIÓN DE LOS ADHESIVOS: SISTEMAS AUTOGRABADORES}

Existen diferentes clasificaciones de los adhesivos en función de distintos parámetros. Siguiendo a Van Meerbeck (6), los sistemas adhesivos modernos se pueden clasificar en tres según su interacción con el barrillo dentinario y no sólo en base al número de pasos de aplicación clínica: los que modifican el barrillo, los que lo remueven y los que lo disuelven (Figura 3).

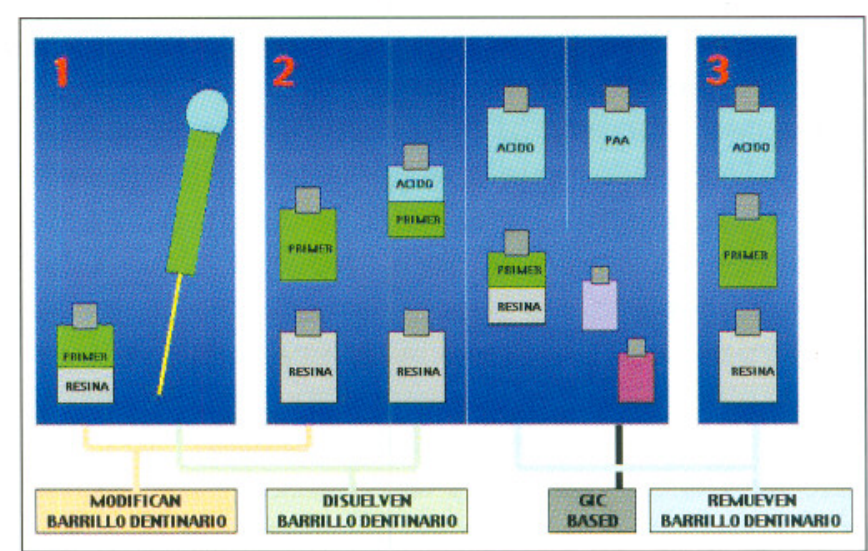

Fig. 3. Clasificación de los adhesivos según Van Meerbek, en función del número de paso y de cómo actúan sobre el barrillo dentinario. 
- Los que modifican el barrillo dentinario pueden constar de uno (PEB 2.1 ó PEB NT) o dos pasos (Probond / Pentra Bond II) y parten del concepto de que el barrillo proporciona una barrera natural a la pulpa protegiéndola frente a la invasión bacteriana y limitando el reflujo del fluido pulpar que podría alterar la unión. Se espera que la adecuada humectabilidad y la polimerización in situ de los monómeros infiltrados en el barrillo refuercen la unión del mismo a la dentina subyacente, formando una unión micromecánica a dentina. Para grabar el esmalte se requiere un acondicionamiento previo selectivo de dicho esmalte. Los restos de barrillo dentinario que tapan los túbulos y llegan a ser infiltrados por resina, formando los llamados "tapones de barrillo impregnados por resina". Su efectividad clínica está en duda.

Algunos de los adhesivos categorizados en este grupo son los que se utilizan en la aplicación de los poliácidos modificados con resina conocidos vulgarmente como compómeros.

En definitiva, modifican el barrillo dentinario para poder infiltrarlo y acceder a la dentina subyacente.

- Los que remueven/eliminan el barrillo dentinario: La mayoría de los adhesivos actuales optan por una completa remoción del barrillo dentinario, de acuerdo con el concepto de grabado total. En su configuración inicial estos sistemas son aplicados en tres pasos para remover el barrillo dentinario. El primer paso consiste en la aplicación superficial de un ácido que desmineraliza la dentina y da lugar a la exposición de un entramado de colágena de 3-7 $\mu \mathrm{m}$. El segundo paso es la aplicación de un imprimador que es el verdadero agente promotor de la adhesión. Contienen monómeros hidrofílicos disueltos en acetona, alcohol y/o agua que penetran en los túbulos de dentina abiertos. Finalmente se dispersa un poco de aire en la superficie para volatilizar el solvente, pero manteniendo la superficie brillante. El tercero de los pasos es la aplicación de una resina normalmente hidrofóbica para asegurar que todo el sistema de irregularidades queda relleno con resina. El resultado de los tres pasos es la conocida capa híbrida por la penetración de la resina entre las fibras de colágena y dentro de los túbulos de dentina abiertos formando los tags de resina.
Estos sistemas adhesivos presentas tres características ultramorfológicas resultantes del proceso de hibridación: la capa híbrida intertubular, la verdadera capa híbrida, con su apariencia de "alfombra" por la pérdida de organización de las fibras de colágena (de hasta $7 \mu \mathrm{m})$. La segunda característica es la hibridación intratubular que representa la extensión de la capa híbrida dentro del área de la pared del túbulo (encontrándose en los cuellos del tag de resina hasta unas 5-10 $\mu \mathrm{m})$. Por último, la hibridación de los túbulos laterales que ha sido descrita como la formación de una delgada capa híbrida dentro de las paredes de las ramas laterales del túbulo.

Esto sería en el caso convencional de que el adhesivo constara de tres pasos. Pero en la actualidad, los hay también de dos pasos, en que el imprimador y la resina son una solución única ("one-bottle system"). En estos casos los fabricantes aconsejan aplicar no una sino múltiples capas de solución adhesiva no sólo para saturar la red de colágena expuesta sino además para proporcionar un espesor de capa adecuado en la zona alta de la capa híbrida. En otros casos se trata de adhesivos que además incorporan a su composición partículas de nanorrelleno.

- Existe un grupo anexo de sistemas adhesivos que son los basados en la tecnología de los ionómeros de vidrio, en los que a parte de una adhesión física aparece un componente químico adicional, que no son el motivo de este artículo.

- Los que disuelven el barrillo dentinario: Finalmente y con objeto de simplificar los procedimientos de aplicación, estos adhesivos cuentan con imprimadores ligeramente acídicos llamados "self-etching primers", cuya función es disolver el barrillo dentinario y desmineralizar parcialmente la superficie de dentina subyacente. Como estos imprimadores no son enjuagados después sino sólo suavemente dispersados, el barrillo dentinario disuelto es incorporado en el proceso de adhesión. La simplificación del proceso clínico se obtiene no sólo por la reducción en los pasos de aplicación, sino especialmente por la eliminación del enjuagado post-condicionamiento del sustrato, evitando de esta manera importantes problemas clínicos como el colapso del colágeno que se produce en el secado con aire después del grabado o el fenómeno de sobremojado que resulta del insu- 
ficiente desplazamiento de las moléculas de agua en la técnica húmeda de adhesión (6). La sensibilidad a la técnica de adhesión asociada a las variaciones en el grado de hidratación de la matriz de colágeno desmineralizado queda eliminada (7).

Los adhesivos autograbadores pueden subdividirse en los 1) "one-step" o "all-in-one" que combinan las tres funciones o 2) los de dos pasos ("two-step") que requieren una aplicación separada de la resina tras la del primer autograbador.

- De acuerdo con su composición, casi todos los adhesivos cuentan con a) HEMA, monómero importantísimo, que por un lado aumenta la capacidad de difusión del preparado en una ambiente húmedo, y por otro actúa como cosolvente para monómeros con dificultad en disolverse en agua; y b) Agua, como componente esencial para permitir la ionización de los monómeros acídicos para la desmineralización de los tejidos duros dentales.

- En los sistemas actuales se presentan dos tipos de moléculas acídicas: por un lado 1) monómeros basados en fosfatos como el MDP, PENTA, HEMAfosfato o di-HEMA-fosfato, HEMA-ester fosfórico; o bien 2) moléculas policarboxílicas como el 4-MET, el copolímero del Vitrebond (que es un ácido polialkenoico), ácidos maleico e itacónico.

Se puede decir que existen autograbadores diferentes en función de su acidez $(\mathrm{pH})$ y por tanto de su agresividad para con el sustrato, en definitiva de la interacción sobre la dentina de los self-etching.

Los sistemas "moderados" que tienen un $\mathrm{pH} \pm$ de 2 (Clearfil SE Bond, Clearfil LB-2V, F2000 y Unifil Bond) dan lugar a una capa híbrida de un grosor de 0 '5 y 1 um. En ella el barrillo dentinario y los tapones de barrillo que obturan los túbulos son incorporados al complejo híbrido, donde también se podría observar una fina capa híbrida propiamente, lo que indica que la resina ha infiltrado y se ha polimerizado con éxito en la red de fibras de colágeno.

Por su parte, los sistemas denominados "fuertes" tienen un $\mathrm{pH}$ de \pm 1 ó menos y por tanto interaccionan más profundamente con la dentina (PLP, NRC+PEB
NT, EtchEPrime). La capa híbrida tiene en estos casos un grosor de 2-3 $\mu \mathrm{m}$ y una apariencia ultraestructural como la de los sistemas multicomponentes de ácido/primer/adhesivo: con el aspecto de alfombra en la zona alta de la capa híbrida, y las características de hibridación intratubular e hibridación de los túbulos laterales.

En cuanto al esmalte, aparentemente requiere una suficiente acidez y agresividad no sólo para remover el barrillo dentinario sino además para producir un adecuado patrón de grabado con microrretenciones. Por tanto, si el autograbador es fuerte puede que aparezcan una especie de microtags pero si es moderado o débil no hay evidencias de interacción con el esmalte. Por lo tanto, son necesarios estudios clínicos controlados para evaluar su eficacia frente a los adhesivos de grabado total.

\section{ADHESIÓN A DENTINA MEDIANTE AGENTES AUTOGRABADORES}

A continuación se van a estudiar tres parámetros de estos sistemas: la microfiltración (su sellado marginal), la fuerza de adhesión, y su caracterización interfacial a partir de imágenes de MEB (Microscopía Electrónica de Barrido).

\section{III.1. Microfiltración}

En trabajos realizados en nuestro grupo de investigación (2), se ha podido observar que los adhesivos autograbadores de dos pasos como el Clearfil SE Bond muestra menos niveles de microfiltración, esto es, presenta mejor sellado marginal que autograbadores "todo-en-uno" como el EtchEPrime, cuya microfiltración no es diferente de sistemas convencionales de tres pasos como el SBMP. Probablemente, las diferencias entre estos sistemas autograbadores sean debidas a una diferente composición química, bien a que se trata de sistemas de diferente aplicación (SE Bond 2 pasos, EEP 1 paso) y a que finalmente se trata de autograbadores con $\mathrm{pH}$ diferentes, con distinta acidez y por tanto con distinta agresividad sobre el sustrato dental (pero no se debe creer en ningún caso que las únicas dife- 


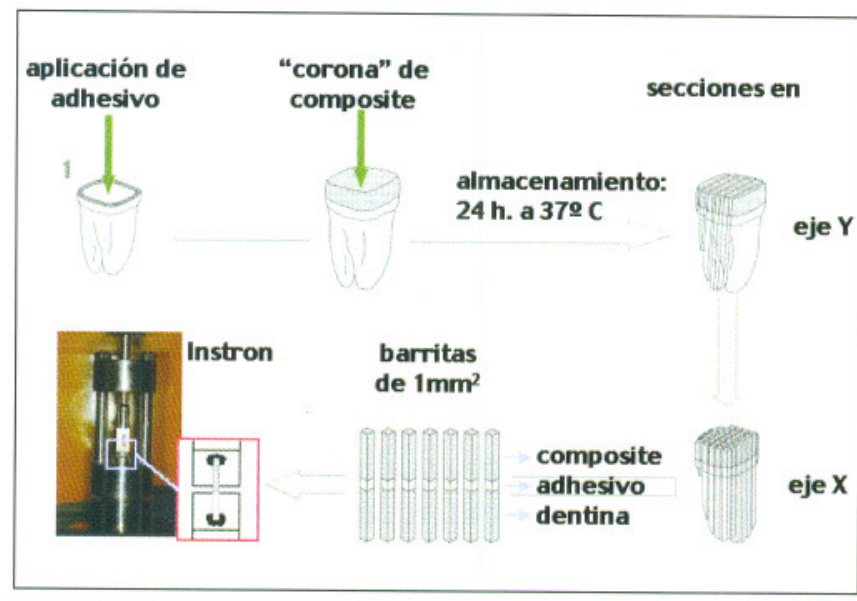

Fig. 4. Esquematización del proceso de preparación demuestras para las pruebas de microtensión.

rencias van a estribar en su acidez, al igual que cuando fracasa una obturación en la consulta lo ha hecho por el sistema de adhesión empleado: son muchos los parámetros y pasos antes y después del adhesivo que pueden hacer fracasar una restauración).

\section{III.2. Fuerza de adhesión ("shear bond strength")}

La técnica de microtensión para evaluar resistencia adhesiva, introducida por Sano y cols. (1994) (8) permite testar la adhesión en áreas muy pequeñas y en diferentes regiones. Aunque se trata de una técnica muy laboriosa, con ella se pueden medir fuerzas de adhesión grandes y obtener de una sola pieza múltiples especimenes. Para la realización del estudio fueron elegidos terceros molares no erupcionados sanos que fueron seccionados perpendicularmente a su eje mayor hasta exponer las superficies de dentina media, superficies que fueron pulidas con discos de SIC/500 grit, obteniendo un área plana. Una vez utilizado el adhesivo de ese grupo, se empleaba el material de restauración con la técnica incremental según instrucciones del fabricante. Todas las muestras se conservaron en agua a $37^{\circ} \mathrm{C}$ durante $24 \mathrm{~h}$. Los dientes fueron seccionados en los ejes " $x$ " e "y" hasta obtener barritas de dentina-adhesivo-composite de $1 \mathrm{~mm}^{2}$ de área adhesiva. Cada especímen se sometió al test de microtensión en una maquina Instron con una velocidad de travesaño de 0,5 $\mathrm{mm} / \mathrm{min}$ y cada área de adhesión fue medida con un micrómetro (Figura 4).
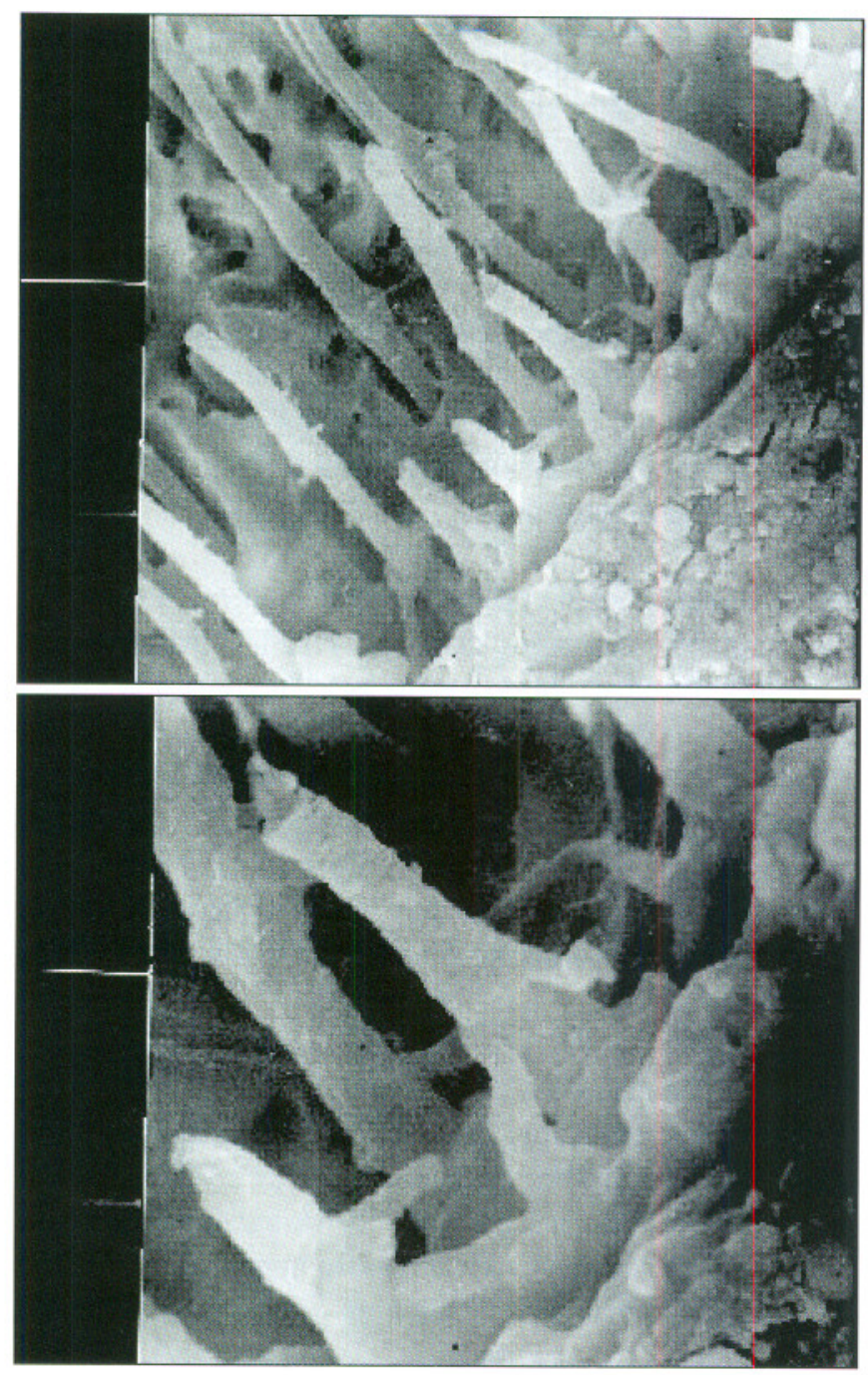

Fig. 5. MEB de un sistema adhesivo convencional de tres pasos (a) con tags más anchos y en forma de embudo; (b) interconexiones entre los tags principales (Tomado de Toledano et al. Am J Dent, 2001).

Los mismos datos que se obtuvieron en microfiltración se pueden apreciar cuando lo que se evalua es la fuerza de adhesión de estos tres sistemas, independientemente del sustrato sobre el que apliquen los sistemas, dentina superficial o profunda, la fuerza de adhesión es mayor en el sistema autograbador de dos pasos en relación al de un paso o al sistema de grabado total convencional. Comparando los dos autograbadores los "todo en uno" no están teniendo buenos resultados en la fuerzas de adhesión en la literatura, posiblemente, como antes se ha indicado, a que la combinación de ácidos y monómeros hidrofílicos e hidrofóbicos en una solución única puede comprometer la función de cada uno de los componentes (2). 


\section{III.3. Caracterización interfacial al MEB}

El Clearfil SE Bond, es decir el autograbador de dos pasos con un ácido débil presenta unos tags de resina estrecho y largos y en esta zona el complejo híbrido; a más aumento se puede apreciar que incluso aparecen interconexiones entre esos tags de resina. Cuando se observa la imagen del EtchEPrime se puede apreciar la capa híbrida también (mayor), pero los tags son unas estructuras mucho más cortas y con forma de embudo que comparados con los que aparecen en la MEB de un sistema adhesivo convencional de tres pasos presenta rasgos muy parecidos: esa importante cantidad de tags, aparecen más anchos y en forma de embudo propios de una mayor penetración de la resina en los túbulos dentinarios (Figura 5a), y no sólo eso, sino además la presencia clara de interconexiones entre los tags principales, indicativos de esa importante desmineralización y posterior difusión de los monómeros (Figura 5b).

\section{PROFUNDIDAD DE DESMINERALIZACIÓN DE LOS IMPRIMADORES DE LOS SISTEMAS AUTOGRABADORES}

No todos los autograbadores van a actuar igual, y serán diferentes principalmente debido, a parte de a su composición, debido a su pH, o sea, a su agresividad con el sustrato de barrillo dentinario, y por fin, en función de su capacidad de penetrar, de profundizar en la dentina durante la fase de desmineralización.

Existen varios factores que influyen en la profundidad de desmineralización: entre estos los 3 primeros están vetados a los fabricantes, y los clínicos no pueden modificar 1) la concentración acídica del primer, 2) las características de viscosidad y de humectabilidad del imprimador, 3) ni el pH (que como hemos visto es de vital importancia) ni el coeficiente de difusión del agente ácido.

Sin embargo, el operador sí puede influir en cuestiones como 4) el tiempo de aplicación de ese imprimador. En el trabajo realizado por Aguilera y cols. (9), con adhesivos autograbadores como el PromptL-Pop en el que, entre otros parámetros, se comparó el tiempo de aplicación indicado por el fabricante,

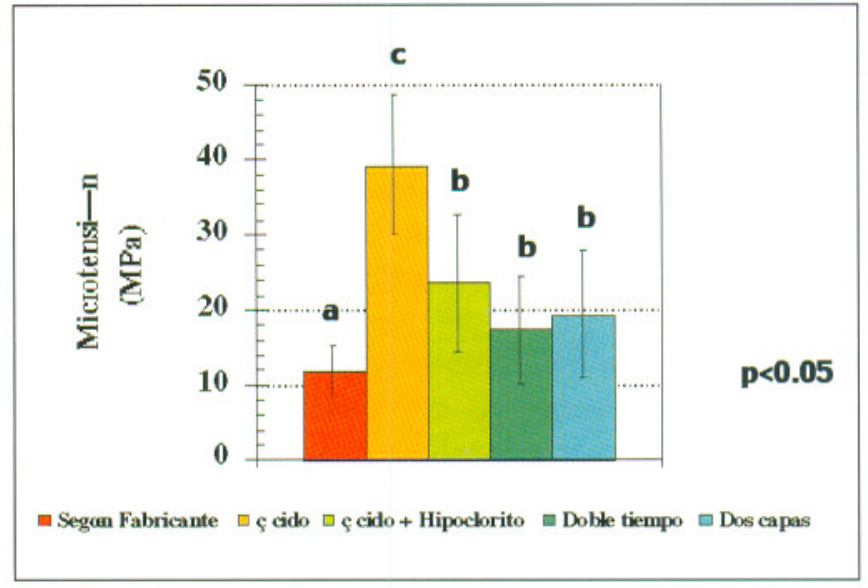

Fig. 6. Se pueden observar las diferencias estadísticamente significativas en las fuerzas de ahesión del Prompt-L-Pop cuando se comprara el tiempo de aplicación del primer indicado por el fabricante, frente al doble de tiempo (Tomado de Aguilera y cols, 2001).

frente al doble de tiempo se pueden observar diferencias estadísticamente significativas aumentando la fuerza de adhesión cuando se aplica el doble de tiempo el primer (Figura 6). Algunos trabajos indican que un mismo adhesivo cuyo $\mathrm{pH}$ aumenta nos puede permitir disminuir el tiempo de aplicación (10). Otros autores mejoran la integridad marginal de las restauraciones aumentando el tiempo de aplicación $(11,12)$.

5) El grosor y la densidad del "empaquetado" del barrillo dentinario. Tras la adición de un sistema autograbador el complejo híbrido resultante se compone de una capa superior y una inferior. La porción superior es producto de la infiltración de la resina en el barrillo dentinario, llamándose barrillo dentinario hibridizado. La porción inferior es debida a la creación de la verdadera capa híbrida en la dentina intertubular desmineralizada. Y además está la presencia de los tapones de barrillo hibridizados formados a partir de los tapones de barrillo dentinario infiltrados por resina. El único eslabón, material que conecta estas dos capas híbridas es la resina que difunde a través de los canales rellenos de fluido del barrillo dentinario (13).

Para que se consiga este complejo híbrido el monómero de resina acídico debe penetrar más allá del barrillo dentinario hasta la dentina parcialmente desmineralizada. Y éste es el peligro de los self-etching: que el grosor del barrillo impida la penetración del 
primer a su través. El grosor de la verdadera capa híbrida es independiente del grosor del barrillo dentinario, según Tay y cols (10), quizás porque la capacidad "buffer" o tampón del barrillo es débil, o porque no actúa tanto como barrera física comparada con la matriz de dentina mineralizada subyacente (12).

Asimismo se ha estudiado cómo influye el pH en el grosor de la verdadera capa híbrida, y los datos muestran que los adhesivos más ácidos obtienen capas híbridas más gruesas, si bien está demostrado que para conseguir unas adecuadas fuerzas de adhesión no es preciso obtener capas híbridas gruesas sino fuertes y uniformes, tan largas como sean las fibras de colágena bien infiltradas con resina (14).

6) Agitación o aplicación dinámica del primer durante el procedimiento clínico. Según datos aun no publicados del Prof. Tay, existe una relación directa entre la profundidad de desmineralización y la agitación del primer del self-etching durante su aplicación si se compara con lo que sería una aplicación estática del mismo.

7) Presencia de agua: También va a depender de la mayor o menor presencia de agua, que va a estar en función de la proximidad a la pulpa de la cavidad. Teóricamente la dentina profunda puede producir altas fuerzas de adhesión debido al aumento de la superficie total disponible para formar la hibridación intra e intertubular. Este potencial beneficio en la unión a dentina profunda (vital) puede no ser tanto a causa de la humedad o presencia de agua concomitante y la conductancia hidráulica asociada con la transudación del fluido dentinal, más característicos de la dentina profunda, sino debida a otros factores (como los relacionados con la humectabilidad, ya vistos anteriormente).

\section{VENTAJAS DE LOS SISTEMAS DE ADHESIÓN AUTOGRABADORES}

Se puede concluir, pues, que los autograbadores son unos sistemas poco sensibles a la técnica y por tanto fáciles de manejar entre otras razones porque:

- no requieren lavado ni secado de la dentina subya- cente solventando así el problema del colapso del colágeno,

- no se afectan por cambios regionales de la dentina a diferencia de los sistemas adhesivos convencionales de tres pasos,

- tampoco se perturban por cambios en la cantidad de agua del sustrato,

- por la no existencia de gaps entre el frente de desmineralización y el frente de infiltración existe una menor sensibilidad postoperatoria.

Así, en la selección de un adhesivo se deberá tener en cuenta si se trata de una restauración en esmalte/ dentina /o cemento, ante qué tipo de dentina se enfrenta el clínico, cuál es la profundidad de la cavidad y cuál va a ser el material de restauración adecuado y elegido, y por último, y no menos importante las preferencias y la sensibilidad, así como todas las características personales propias del operador.

\section{AGRADECIMIENTOS}

Para la realización de este trabajo ha sido importante la financiación económica recibida por los proyectos de la Comisión Interministerial MAT98-0937-C02 y MAT2001-2843-C02. Los autores manifiestan su agradecimiento al grupo de investigación "Biomateriales y Salud Laboral en Odontología" (Universidad de Granada CTS 0242) y a la señorita Gertrudis Gómez Villaescusa por su asistencia en el laboratorio.

\section{BIBLIOGRAFÍA}

1. Adhesión en odontopediatría. Toledano $M$, Osorio R, EN: Materiales de uso frecuente en Odontopediatría. Edit. Buho, Republica Dominicana 2000.

2. Toledano M, Osorio R, de Leonardi G, RosalesLeal JI, Ceballos L, Cabrerizo-Vilchez MA. 
Influence of self-etching primer on the rsin adhesión to enamel and dentin. Am J Dent 2001; 14: 205-10.

3. Eick JD, Gwinnett AT, Pashley DH, Robinson SJ. Current concepts on adhesion to dentin. Crit Rev Oral Biol Med 1997; 8 (3): 306-35.

4. Watanabe $\mathrm{Y}$, Nakabayashi $\mathrm{N}$, Pashley $\mathrm{DH}$. Bonding to ground dentin by a Phenyl -P selfetching primer. J Dent Res 1994; 73 (6): 121220.

5. Tay FR, Carvalho R, Sano H, Pashley DH. Effect of smear layer on the bonding of a self-etching primer to dentin. J Adhesive Dent 2000; 2: 99116.

6. Van Meerbek B, Perdigao J, Lambrechts P, Vanherle G. The clinical performance of adhesives. J Dent 1998; 26: 1-20.

7. Pashley DH, Tay FR Agressiveness of contemporary self-etching adhesives. Part II: etching effects on unground enamel. Dent Mater 2001; 17: 40344.

8. Sano H, Shono T, Sonoda H, Takatsu T, Ciuchi B, Carvalho R, Pashley DH. Relationship betwen surface area for adhesión and tensile bond strenght. Evaluation of a micro-tensile bond test. Dent Mater 1994; 10: 236-40.
9. Aguilera FS, Osorio E, Osorio R, Toledano M. Influencia de los parámetros de aplicación en la fuerza de adhesión del sistema autograbador Prompt L-Pop. IX Congreso Nacional de la SEOC y I Hispano-Luso de Odontología Conservadora, Oviedo, España 2001.

10. Tay FR, Sano H, Carvalho R, Pashley EL, Pashley $\mathrm{DH}$. An ultraestructural study of the influence of the acidity of self-etching primers and smear layer thickness on bonding to intact dentin. $\mathrm{J}$ Adhesive Dent 2000; 2: 83-98.

11. Ferrari M, Mannocci F, Vichi A, Davidson CL. Effect of two etching times on the sealing ability of Clearfil Liner Bond 2 in Class V restorations. Am J Dent 1997; 10: 66-70.

12. Tay FR, Pashley DH. Agressiveness of contemporary self-etching adhesives. Part I: Depth of penetration beyond dentin smear layers. Dent Mater 2001; 17: 296-308.

13. Pashley DH, Horner JA, Brewer PD. Interactions of conditioners on the dentinsurface. Oper Dent Suppl 1992; 5: 137-50.

14. Inoue S, Van Meerbeek, Vargas M, Yoshida Y, Lambrechts P, Vanherle G. Adhesión mechanism of self-etching adhesives. EN: Advanced Adhesive Dentistry, 3rd International Kuraray Symposium: Tagami J, Toledano M, Prati C. Granada, Spain, 1999. 
